\title{
Relationship between Surface Temperature and Extreme Rainfalls: A Multi-Time-Scale and Event-Based Analysis**
}

\author{
Gérémy Panthou, Alain Mailhot, Edward Laurence, and Guillaume Talbot \\ Centre Eau, Terre et Environnement, Institut National de la Recherche Scientifique, Québec, Québec, Canada
}

(Manuscript received 20 January 2014, in final form 28 May 2014)

\begin{abstract}
Recent studies have examined the relationship between the intensity of extreme rainfall and temperature. Two main reasons justify this interest. First, the moisture-holding capacity of the atmosphere is governed by the Clausius-Clapeyron (CC) equation. Second, the temperature dependence of extreme-intensity rainfalls should follow a similar relationship assuming relative humidity remains constant and extreme rainfalls are driven by the actual water content of the atmosphere. The relationship between extreme rainfall intensity and air temperature $\left(P_{\text {extr }}-T_{a}\right)$ was assessed by analyzing maximum daily rainfall intensities for durations ranging from $5 \mathrm{~min}$ to $12 \mathrm{~h}$ for more than 100 meteorological stations across Canada. Different factors that could influence this relationship have been analyzed. It appears that the duration and the climatic region have a strong influence on this relationship. For short durations, the $P_{\text {extr }}-T_{a}$ relationship is close to the CC scaling for coastal regions while a super-CC scaling followed by an upper limit is observed for inland regions. As the duration increases, the slope of the relationship $P_{\text {extr }}-T_{a}$ decreases for all regions. The shape of the $P_{\text {extr }}-T_{a}$ curve is not sensitive to the percentile or season. Complementary analyses have been carried out to understand the departures from the expected Clausius-Clapeyron scaling. The relationship between dewpoint temperature and extreme rainfall intensity shows that the relative humidity is a limiting factor for inland regions, but not for coastal regions. Using hourly rainfall series, an event-based analysis is proposed in order to understand other deviations (super-CC, sub-CC, and monotonic decrease). The analyses suggest that the observed scaling is primarily due to the rainfall event dynamic.
\end{abstract}

\section{Introduction}

Extreme rainfalls are the main factor generating floods, landslides, or soil erosion and thus can cause environmental, societal, and economical damages. Global warming is expected to intensify the global water cycle (Huntington 2006). Climate model simulations (Kharin et al. 2007, 2013; Pall et al. 2007; Sun et al. 2007; Mailhot et al. 2012), observation series (Easterling et al. 2000; Alexander et al. 2006; Allan and Soden 2008; Min et al. 2011), and theoretical considerations (Allen and Ingram 2002; Trenberth et al. 2003; O'Gorman and Schneider

\footnotetext{
* Supplemental information related to this paper is available at the Journals Online website: http://dx.doi.org/10.1175/JHM-D-140020.s1.

Corresponding author address: Gérémy Panthou, INRS-Eau, Terre et Environnement, 490 de la Couronne, Québec, QC G1K 9A9, Canada.

E-mail: geremy.panthou@ete.inrs.ca
}

2009) support the hypothesis of an increase in the frequency and intensity of extreme rainfalls in a warming climate.

The primary process involved in the increase of extreme rainfall with temperature is the ability of a warmer atmosphere to hold more moisture. The ClausiusClapeyron (CC) equation indicates that the rate of increase of the atmospheric moisture-holding capacity is approximately $7 \% \mathrm{~K}^{-1}$ of warming (called the CC scaling). In fact, the $\mathrm{CC}$ scaling decreases with temperature $\left(7.3 \% \mathrm{~K}^{-1}\right.$ at $0^{\circ} \mathrm{C}, 6.4 \% \mathrm{~K}^{-1}$ at $15^{\circ} \mathrm{C}$, and $6.0 \% \mathrm{~K}^{-1}$ at $25^{\circ} \mathrm{C}$ ). The $\mathrm{CC}$ scaling is regularly approximated by different values between $6 \%$ and $7 \% \mathrm{~K}^{-1}$ in the literature, for example, $\sim 6 \%-7 \% \mathrm{~K}^{-1}$ (Schneider et al. 2010), $\sim 6.5 \% \mathrm{~K}^{-1}$ (Pall et al. 2007), $6.8 \% \mathrm{~K}^{-1}$ (Hardwick Jones et al. 2010), and $\sim 7 \% \mathrm{~K}^{-1}$ (Lenderink and van Meijgaard 2010; Lenderink et al. 2011; Shaw et al. 2011; Trenberth 2011). In this study, a value of $7 \% \mathrm{~K}^{-1}$ for the $\mathrm{CC}$ scaling is used in order to be consistent with most of the references cited hereinafter (e.g., Lenderink and van Meijgaard 2008; Haerter et al. 2010; Berg et al. 2013). 
Trenberth et al. (2003) predict that extreme rainfall intensities will increase at the same rate as the atmospheric moisture-holding capacity. The CC scaling of extreme rainfall intensities with air temperature is based on the three following hypotheses: (i) relative humidity remains approximately constant in a future climate, (ii) intense rainfalls are mainly determined by the actual water content of the atmosphere, and (iii) the atmospheric circulation will not change considerably in a future climate. Inspired by these considerations, many authors have studied the relationship between extreme rainfall intensity and surface air temperature (hereafter $P_{\text {extr }}-T_{a}$ relationship) using historical records.

The pioneering work by Lenderink and van Meijgaard (2008) analyzed a 99-yr record of hourly rainfall for a station located in the Netherlands. These authors observed a super-CC scaling. The relationship between extreme rainfall intensities and daily temperature was found to be roughly 2 times the $\mathrm{CC}$ scaling when daily temperatures exceeded $12^{\circ} \mathrm{C}$. Based on these results, others have been motivated to investigate the $P_{\text {extr }}-T_{a}$ relationship in different regions (e.g., Haerter et al. 2010; Hardwick Jones et al. 2010; Utsumi et al. 2011; Mishra et al. 2012). In these studies, four types of $P_{\text {extr }}-T_{a}$ relationship were reported: (i) rainfall intensity increases monotonically with temperature, (ii) rainfall intensity decreases monotonically with temperature, (iii) rainfall intensity increases with temperature and levels off at high temperature (upper limit structure), and (iv) rainfall intensity increases with temperature and decreases after reaching a maximum (peak-like structure). For all increasing slopes, the relationship between temperature and rainfall intensity can either be sub-CC, close-CC, or super-CC.

Different factors can influence the $P_{\text {extr }}-T_{a}$ relationship. The following main factors are mentioned in the literature:

- Percentile: Hardwick Jones et al. (2010) found a monotonic decrease for the median intensity but a monotonic increase for the 99th percentile in southern Australia. Other studies have found that different $P_{\text {extr }}-T_{a}$ patterns can be obtained for the 90th and 99th percentiles (Lenderink and van Meijgaard 2008, 2010).

- Season (see, e.g., Berg et al. 2009; Mishra et al. 2012; Shaw et al. 2011): For Europe, Berg et al. (2009) found a monotonic increase structure in winter, a monotonic decrease structure in summer, and a peak-like structure for spring and autumn.

- Time scale: Many studies have shown that the time scale over which extreme rainfall events are estimated has a huge impact on the $P_{\text {extr }}-T_{a}$ relationship (Lenderink and van Meijgaard 2008; Haerter et al. 2010; Hardwick
Jones et al. 2010; Utsumi et al. 2011). For instance, a super-CC can be observed for hourly rainfall but not for daily rainfall (see, e.g., Lenderink and van Meijgaard 2008). As reported by Hardwick Jones et al. (2010) and Utsumi et al. (2011), CC scaling is usually found at subdaily time scales even if a peak-like structure is present for daily rainfall. On this point, a comprehensive study has been carried out by Haerter et al. (2010), which showed, using six meteorological stations located in different regions of Germany, that shorter time scales display larger increasing rates of rainfall intensity with temperature.

- Region: Geographical regions also have a strong impact on the relationship between extreme rainfall and temperature. Utsumi et al. (2011) reported results from a worldwide analysis of the $P_{\text {extr }}-T_{a}$ relationship. The authors reported monotonic increases in extreme rainfall (95th percentile of daily rainfall intensity) with surface temperature for high latitudes $\left(>55^{\circ} \mathrm{N}\right)$, peak-like structures for midlatitudes $\left(20^{\circ}-55^{\circ} \mathrm{N}\right.$ and $20^{\circ}-55^{\circ} \mathrm{S}$ ), and monotonic decreases in the tropics $\left(20^{\circ} \mathrm{S}-20^{\circ} \mathrm{N}\right)$. This general picture has been confirmed by various regional studies in tropical regions (Hardwick Jones et al. 2010; Maeda et al. 2012) and in mid-to-high latitudes (Lenderink and van Meijgaard 2008, 2010; Shaw et al. 2011; Berg et al. 2013; Berg and Haerter 2013, among others). But, as pointed out by Shaw et al. (2011), the $P_{\text {extr }}-T_{a}$ relationship varies from region to region, and latitude cannot solely explain the nature of this dependence.

In this study, we assess the $P_{\text {extr }}-T_{a}$ relationship using datasets from contrasting climatic regions across Canada. Two studies have explored the relationship between hourly rainfall intensity and daily temperature across the United States (Shaw et al. 2011; Mishra et al. 2012). To our knowledge, this study is the first attempt to characterize the dependence between temperature and extreme rainfall intensity across Canada.

Two issues are investigated in this paper. First, we examine the relationship between air temperature and rainfall intensity and attempt to identify the main factors (percentile, season, temporal scale, and region) affecting the $P_{\text {extr }}-T_{a}$ relationship. Then, we investigate the various observed relationships and aim to outline possible explanations. Accordingly, two complementary analyses are proposed: (i) the dependence of extreme rainfall on the dewpoint temperature $\left(P_{\text {extr }}-T_{d}\right.$ relationship) is first investigated to verify whether humidity limits the increase of extreme rainfall intensity with temperature, and (ii) an event-based analysis is carried out in order to reveal the impact of increasing temperature on event characteristics. 


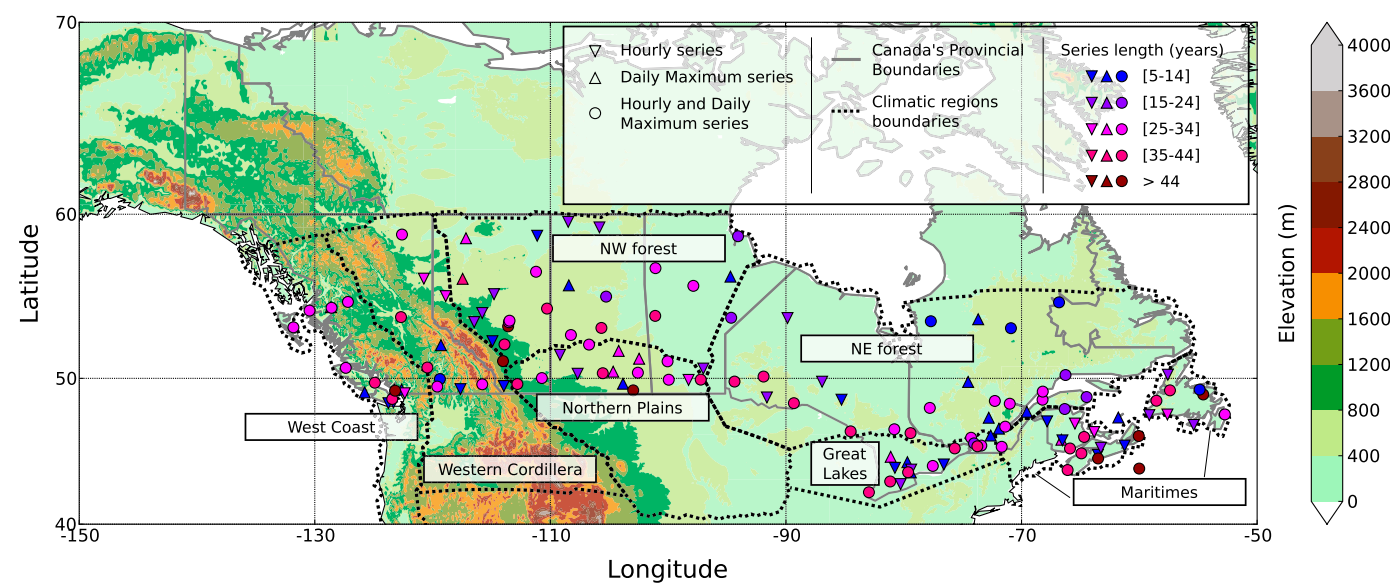

FIG. 1. Stations considered in the study. The background map displays the elevation $(\mathrm{m})$. The length of the series is indicated by the color of the points.

The paper is organized as follows. The available datasets are presented in the next section. In sections 3 and 4 , the $P_{\text {extr }}-T_{a}$ and $P_{\text {extr }}-T_{d}$ relationships are evaluated. The event-based analysis is presented in section 5, followed by a discussion and conclusions in section 6 .

\section{Available datasets}

Rainfall and temperature data used in this study were recorded by the station networks operated by the Ministère du Développement Durable, de l'Environnement et des Parcs (MDDEP; Québec) and Environment Canada. Two datasets were used in this study.

The first dataset contains a series of daily maximum rainfalls for durations of 5, 10, 15, and $30 \mathrm{~min}$ and $1,2,6$, and $12 \mathrm{~h}$. Each value corresponds to the maximum rainfall recorded during a given duration, on a given day. Since these values are obtained from a fixed time window [from 0000 to 0000 local time (LT)], it underestimates the true maximum daily rainfall (obtained from a moving time window), especially for longer durations. Data are available for the May-October period (stations are not operated during winter). These rainfall series are used to estimate intensity-duration-frequency curves in Canada (Canadian Standards Association 2012). Mean daily air temperature and dewpoint temperature series are also available for these stations, and they were considered to study the $P_{\text {extr }}-T_{a}$ and $P_{\text {extr }}-T_{d}$ relationships. These stations will be referred to as daily maximum (DM) stations or the DM dataset in the following sections.

The second dataset consists of hourly rainfall, mean daily air temperature, and mean daily dewpoint temperature series. Periods during which gauging stations are operated vary from year to year and from station to station, but all stations are operated in summer and some in autumn (very few have records during winter). Therefore, only the May-October period was considered in this study. These data were used to extract rainfall events and thus to carry out the event-based analysis. To compare the evolution of event rainfall characteristics with temperature, the "midtime" of the events was used to assign event characteristics to a given day (since temperature series are on a daily basis). The midtime of a rainfall event corresponds to the mean of all wet dates of the event.

These two datasets have been quality checked and obvious errors have been flagged as missing data (maximum daily amount for a given duration is higher than the amount for a longer duration, dewpoint temperature higher than air temperature, etc.). A given day was considered as missing when one value was missing among the different series (air temperature, dewpoint temperature, or rainfall). A year was considered valid when daily missing data represented less than $20 \%$ of the period May-October for that year. Only stations with more than 5 years of valid data were considered. This quality control procedure resulted in the exclusion of some stations and years from the original datasets. From 157 (158) stations available in the hourly (DM) dataset, 28 (48) stations have been removed because they contained less than 5 years of valid data, and 507 (413) station-years lacking more than $20 \%$ of the daily data have been removed from the remaining series.

The stations were grouped into seven regions with distinct climatological characteristics (Plummer et al. 2006): Great Lakes, Maritimes, Northeast Forest (NE Forest), Northwest Forest (NW Forest), Northern Plains, West Coast, and Western Cordillera (Fig. 1). Stations from the northern regions (East Arctic, Mackenzie, and Yukon) were not considered in this study because not 
TABLE 1. Number of series considered and length (yr) of the shortest and longest series for each region.

\begin{tabular}{lccccc}
\hline \hline & Hourly stations & DM stations & Hourly and DM stations & Shortest series & Longest series \\
\hline Great Lakes & 13 & 13 & 9 & 6 & 5 \\
Maritimes & 25 & 16 & 14 & 5 & 46 \\
NE Forest & 22 & 23 & 18 & 6 & 45 \\
NW Forest & 21 & 17 & 13 & 9 & 5 \\
Northern Plains & 12 & 13 & 8 & 8 & 45 \\
West Coast & 11 & 12 & 7 & 45 & 47 \\
Western Cordillera & 11 & 8 & 78 & & 47 \\
Total & 115 & 102 & & & 5 \\
\hline
\end{tabular}

enough data were available (there are less than six stations for each of these three regions). In summary, the hourly and DM datasets used in the following sections include 115 and 102 stations and contain 3224 and 2976 station-years, respectively. The number of stations in each region is presented in Table 1 and varies from 8 to 25 .

\section{Relationship between extreme rainfall intensity and surface temperature}

The $P_{\text {extr }}-T_{a}$ relationship is presented in this section using maximum daily rainfall intensities (DM dataset). A procedure similar to the one proposed by Lenderink and van Meijgaard (2008) was used. Maximum daily rainfall intensities larger than $0.3 \mathrm{~mm} \mathrm{~h}^{-1}$ were considered for each duration. Maximum daily rainfall intensities were classified according to the corresponding mean daily air temperature. As proposed by Lenderink and van Meijgaard (2010), temperature bins were defined by moving a $2^{\circ} \mathrm{C}$ width window every $1^{\circ} \mathrm{C}$ (overlapping bins) to avoid the choice of odd or even bin limits. For each bin, the reference temperature corresponds to the mean temperature. The distribution of rainfall intensities was then constructed within each temperature bin. Bin statistics (e.g., 90th, 95th, and 99th percentiles) were computed when a bin included more than 100 sampled rainfall intensities. Confidence intervals on intensity statistics within each bin temperature were estimated using a nonparametric bootstrap (Efron and Tibshirani 1994). The Monte Carlo case resampling algorithm was used to compute percentile bootstrap confidence intervals. For a given bin of temperature, the rainfall intensities were resampled with replacement until the size of the bootstrap sample equals the number of data in the bin. Then the percentile of interest was computed on this bootstrap sample. These two steps were repeated 1000 times. The confidence intervals were computed using these 1000 samples. This procedure proposed by Efron (1979) is called "percentile bootstrap intervals" or "percentile bootstrap confidence intervals" (Wehrens et al. 2000).
The relationship between extreme rainfall intensity and temperature is not sensitive to the percentile used. More precisely, very similar patterns were observed between the 90th and 99th percentiles (see Figs. 1-4 in supplemental material). The 95th percentile will be considered in the following text. This percentile was chosen because: (i) it is representative of extreme rainfalls and (ii) the confidence intervals remain reasonably narrow. Given this last point and the large number of observations used, the difference between empirically estimated percentiles and percentiles estimated with a parametric approach (e.g., fitting a generalized Pareto distribution to intensities and obtaining the corresponding percentiles) is small. Empirical percentiles are used in the following.

Figure 2 presents the observed scaling for the 95th percentile of rainfall intensity as a function of mean daily air temperature for 5-, 10-, 15-, and 30-min and 1-, 2-, 6-, and 12-h durations (period May-October). Regardless of the region, the main factor that influenced the $P_{\text {extr }}-T_{a}$ relationship was the duration. For short durations (less than or equal to $1 \mathrm{~h}$ ) and below $20^{\circ} \mathrm{C}$, the rainfall intensity increased with temperature. A general shift from a close-CC or super-CC scaling to a sub-CC scaling was observed with increasing durations. For the longest durations ( 6 and $12 \mathrm{~h}$ ), the slope was close to zero or even negative.

When comparing the results from the different regions, two distinct behaviors were observed, one for coastal regions and the other for inland regions. The relationship for coastal regions (West Coast and Maritimes) varied from a monotonic increase around the CC scaling (without upper limit) for short durations to a monotonic decrease (West Coast) or a slope close to zero (Maritimes) for longer durations. Inland regions (Great Lakes, Northern Plains, Western Cordillera, NE Forest, and NW Forest) were characterized by a super-CC scaling (ranging from $9 \%$ to $10 \% \mathrm{~K}^{-1}$ ) between $10^{\circ}$ and $20^{\circ} \mathrm{C}$ for short subhourly durations followed by an upper limit (NE Forest and NW Forest) or a peak-like structure (Great Lakes, Northern Plains, Western Cordillera). For longer 

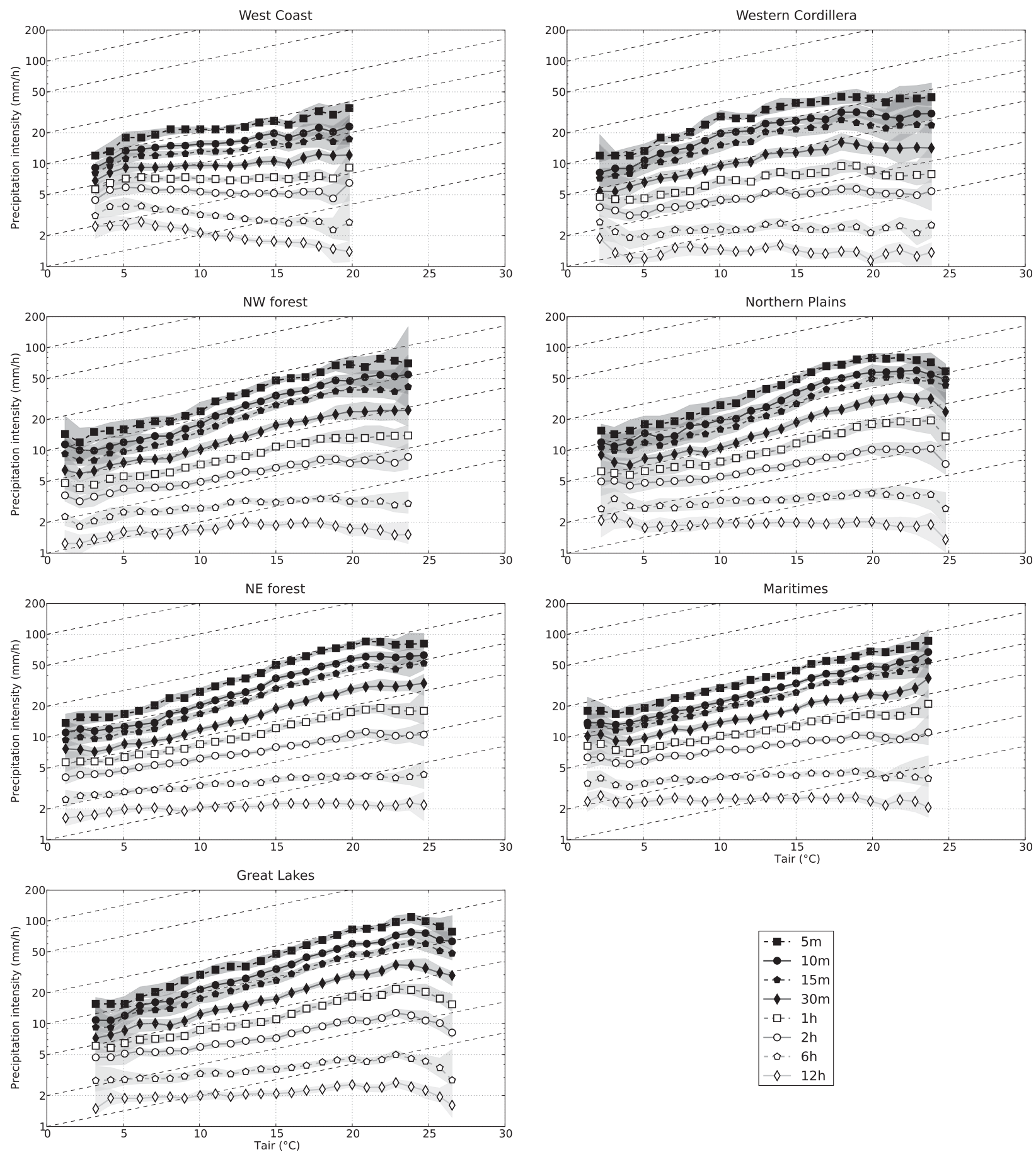

FIG. 2. The 95th percentile of rainfall intensity as a function of mean daily air temperature for 5-, 10-, 15-, and 30-min and 1-, 2-, 6-, and 12-h durations (period May-October). Shaded areas delineate $95 \%$ confidence intervals. Dashed lines correspond to the $7 \% \mathrm{~K}^{-1} \mathrm{CC}$ scaling. Note the logarithmic $y$ axis.

durations, these regions were characterized by a sub-CC scaling.

The dependence of the $P_{\text {extr }}-T_{a}$ relationship on season was also analyzed (see Fig. 5 in the supplemental material). It appears that seasons have a minor impact on scaling relationships. The temperature ranges of each season are different but the overall shape and values of $P_{\text {extr }}-T_{a}$ relationships are similar. Larger confidence 
intervals (due to the smaller number of samples within each temperature bin) are estimated for seasonal analysis when compared to the May-October period. The entire May-October period is considered in the following.

Based on these results, further analyses are needed to understand the observed $P_{\text {extr }}-T_{a}$ relationships. Two main questions arise:

(i) Why does the $P_{\text {extr }}-T_{a}$ relationship depart from CC scaling in many cases? More precisely, why are super-CC, level-off, peak-like structures (inland regions), and monotonic decreases (coastal regions) observed? and

(ii) What can explain the observed differences between coastal and inland regions?

To answer these questions, one might investigate the validity of the two main assumptions underlying the hypothesis of CC scaling, namely, that (i) the relative humidity remains constant as air temperature rises and (ii) extreme rainfall intensities are mainly driven (or conditioned) by the actual content of water in the atmosphere.

\section{Relationship between extreme rainfall intensity and dewpoint temperature}

The same methodology has been applied to study the link between dewpoint temperatures and extreme rainfall intensities $\left(P_{\text {extr }}-T_{d}\right.$ relationship). As pointed out by Lenderink and van Meijgaard (2010), if relative humidity remains constant as temperature increases, then the dewpoint depression (which is the difference between air temperature and dewpoint temperature) is approximately constant with temperature. Therefore, the increase of specific humidity in the air column follows the increase in air moisture-holding capacity. If so, the relationship between dewpoint temperature and extreme rainfall intensity $\left(P_{\text {extr }}-T_{d}\right)$ would have a similar shape to the relationship between air temperature and extreme rainfall intensity $\left(P_{\text {extr }}-T_{a}\right)$. In this case, the $P_{\text {extr }}-T_{d}$ relationship is just a translation of the $P_{\text {extr }}-T_{a}$ relationship (the translation is equal to the dewpoint depression). If the relative humidity changes as the temperature rises, then $P_{\text {extr }}-T_{a}$ and $P_{\text {extr }}-T_{d}$ relationships will have different shapes.

Figure 3 illustrates the dependency of extreme rainfall intensity on dewpoint temperature. For coastal regions (West Coast and Maritimes), the resulting $P_{\text {extr }}-T_{d}$ relationships are very similar to the $P_{\text {extr }}-T_{a}$ relationships. In this case, the humidity does not seem to limit the increase of extreme rainfall intensity with temperature. The sub-CC scalings observed for longer durations (both for $P_{\text {extr }}-T_{a}$ and $P_{\text {extr }}-T_{d}$ ) suggest that the relative humidity does not explain this departure from CC scaling.

For inland regions, the peak-like and upper limit structures have disappeared (Great Lakes, NW Forest, and Western Cordillera) or have been strongly smoothed off (NE Forest and Northern Plains). This suggests that humidity is a limiting factor for these regions when the air temperature is greater than around $20^{\circ} \mathrm{C}$. For inland regions, the super-CC and sub-CC scalings are also observed for short and long durations, respectively, as well as for the $P_{\text {extr }}-T_{a}$ relationship, suggesting that the relative humidity does not explain these two departures from a CC scaling.

\section{Event-based analysis}

An event-based analysis of rainfall is proposed to investigate two issues in this section. The first concerns the presence of a super-CC scaling for subhourly time scales in inland regions. One can argue, as already proposed by Haerter and Berg (2009), that scaling relationships are governed by a shift in rain type as temperature increases, moving from a more synoptic type for lower temperatures to a more convective type for higher temperatures. This hypothesis was suggested by Haerter and Berg (2009) to explain the super-CC scaling reported by Lenderink and van Meijgaard (2008) and the fact that it was observed at the hourly time scale and not the daily time scale. In their response, Lenderink and van Meijgaard (2009) propose another explanation. They argue that the super-CC scaling has a physical origin that is related to a convective event rainfall dynamic. Our results also suggest the existence of this super-CC scaling for the shortest time scales for midrange temperatures in inland regions. Thus, the question is, is the observed super-CC relationship the result of a shift in rainfall types, as suggested by Haerter and Berg (2009), or is it the result of a rainfall event dynamic, as proposed by Lenderink and van Meijgaard (2009)?

The second question is, why are the slopes of the $P_{\text {extr }}-T_{a}$ and $P_{\text {extr }}-T_{d}$ relationships more pronounced for shorter than for longer durations? As explained by Haerter et al. (2010), longer durations mean that dry or less intense subperiods may be included in the considered rainfall duration, and this certainly has an impact on the resulting extreme rainfall intensity-temperature relationship. However, one can also argue that longduration rainfall events are less dependent than shorter events on local air temperature and humidity.

\section{a. Rainfall event definition and characteristics}

The subdivision of rainfall records into rainfall events is generally achieved by specifying a minimum event 

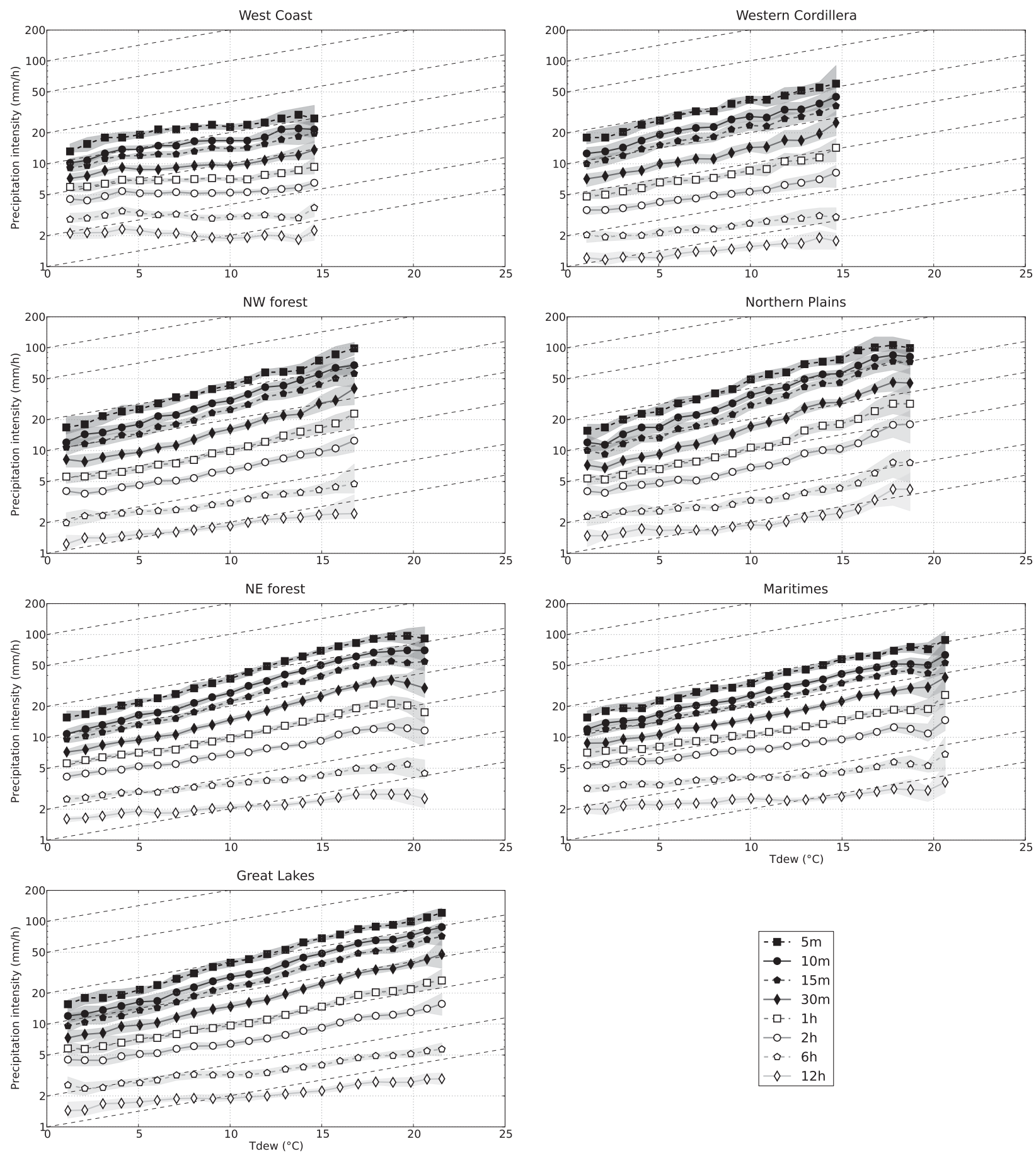

FIG. 3. As in Fig. 2, but for mean daily dewpoint temperature.

depth and a minimum interevent time (MIT). Many values have been proposed in the literature depending on the objectives of the rain event identification. For more details on the impact of the MIT criterion on rain event characteristics, the reader is referred to the comprehensive study of Dunkerley (2008).
In our case, rainfall events were defined according to the following criteria: (i) a threshold value of $0.3 \mathrm{~mm} \mathrm{~h}^{-1}$ defines a "wet" hour (if hourly rainfall depth is smaller than $0.3 \mathrm{~mm}$ it is reported as a "dry" hour) and (ii) a rainfall event is made of a succession of wet hours preceded and followed by dry periods of $6 \mathrm{~h}$ or more. A 
sensitivity analysis on these two parameters (the threshold and the MIT) was performed and demonstrates that these definitions have no significant impacts on the reported results and conclusions. The minimum hourly rainfall depth defining a wet hour (threshold value of $0.3 \mathrm{~mm} \mathrm{~h}^{-1}$ ) was defined to account for possible changes in rainfall series (e.g., break points) due to changes in rain gauge resolution or transition from English units to the metric system in the 1970s (Metcalfe et al. 1997).

Hourly rainfall series were subdivided into events and the following event characteristics were estimated: total duration, total depth, mean intensity, maximum intensity, and wet time fraction. The wet time fraction is defined as the ratio between the total duration of wet hours during an event and the total duration of the event. It is an adaptation of the formula proposed by Utsumi et al. (2011), who computed the wet time fraction for days exceeding the 90th percentile of daily precipitation. Since hourly rainfall series were used, mean intensity and maximum intensity could be strongly underestimated, especially for short events (events which have a recorded duration of $2 \mathrm{~h}$ or less). These event characteristics were thus not used in the following. Mean daily temperatures (air and dewpoint) corresponding to the date of occurrence of rainfall events were also extracted from available series.

\section{b. Event rainfall duration versus temperature}

To investigate possible changes in terms of rainfall type, rain events were classified in three classes of durations: short- (SDEs; $1-2 \mathrm{~h}$ ), mid- (MDEs; $3-10 \mathrm{~h}$ ), and long-duration events (LDE; more than $10 \mathrm{~h}$ ). It is assumed that convective processes dominate for shortduration events, that long-duration events are mainly associated with synoptic systems or to the orographic effect, and that midduration events are associated with combined or embedded convective and synoptic systems (Hand et al. 2004; Canadian Standards Association 2012). Working in terms of event duration classes more closely matches the processes involved in rainfall generation.

Figure 4 presents the relationship between temperature and the fraction of rainfall events in each duration class event exceeding the 80th percentile of rainfall event depth (ranging from $6.9 \mathrm{~mm}$ for Western Cordillera to $14.0 \mathrm{~mm}$ for Maritimes). Similar results are obtained when considering the dewpoint temperature instead of air temperature (see Fig. 6 in the supplemental material). Other percentiles have been tested and the general pattern of each curve did not change substantially. The main impacts of percentile are the repartition between SDE and LDE (as percentile increases, the fraction of LDE increases and the fraction of SDE decreases) and the presence of SDE at low temperatures when all events are considered (or low percentiles are used). For all regions, as temperature increases, SDE fractions monotonically increase; MDE fractions first increase and then reach an upper limit; and, finally, LDE fractions monotonically decrease. This suggests that the atmospheric instability increases with temperature, therefore increasing the probability of occurrence of convective events. Coastal regions (especially the West Coast) have a very small fraction of SDE associated with high percentile event depths. Therefore, extreme rainfalls seem to be more likely generated by synoptic systems. For inland regions, SDEs dominate at higher temperatures. As temperature increases, there is a clear shift from a regime where longduration events occur more frequently to a regime where short-duration events prevail. As expected, it suggests a transition from a synoptic to a more convective regime with increasing temperature.

\section{c. Event rainfall depth versus air temperature}

As suggested by the previous analysis and as reported by Hand et al. (2004), one can use event duration to discriminate between synoptic and convective rainfall types, given that the event depth is sufficiently high. The $P_{\text {extr }}-T_{a}$ relationship is estimated for each class of event duration. It is expected that the temperature-rainfall relationship for each duration class is more strongly related to one rainfall regime (synoptic or convective) since the relationship is computed for each class of event and each class of event is assumed to be associated with a dominant rainfall process (especially SDE and LDE).

Figure 5 shows the relationship between extreme event depth (95th percentile) and temperature for events within each class of duration and for all durations. Two general comments are valid for all regions: LDEs brought much more rain than SDEs and the slope of the event depth relationship with temperature is more pronounced for SDEs than for LDEs. The SDE depth relationship with temperature is a super-CC, except for West Coast and Western Cordillera (sub-CC scaling and close-CC scaling, respectively). For LDE, the scaling between event depth and temperature is sub-CC. Although rainfall event depths increase with temperature for all duration classes, rainfall event depths do not display a clear dependence on temperature when all durations are considered (black stars on Fig. 5; except for West Coast, for which a peak-like structure is observed). This may be explained by the transition from a high fraction of long-duration events to a high fraction of SDE as the temperature increases (see Fig. 4). One noteworthy feature is the presence of a super-CC scaling for SDE for temperatures higher than $10^{\circ}-15^{\circ} \mathrm{C}$ (except for West Coast). The slope of the relationship is even 

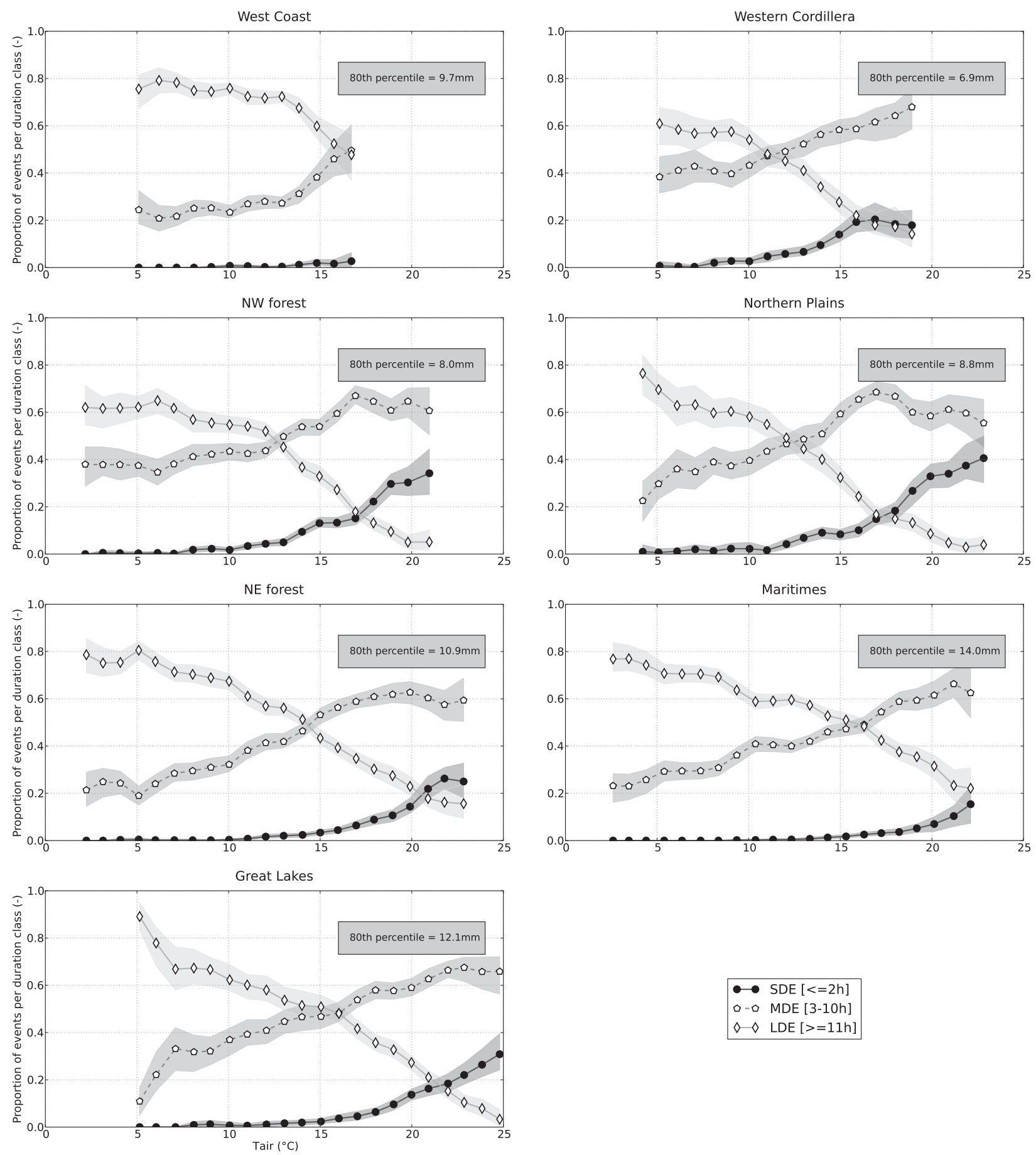

FIG. 4. Fractions of SDEs, MDEs, and LDEs as a function of surface air temperature for events with depth above the 80th percentile (value indicated in the gray boxes for each regions). Shaded areas represent the $95 \%$ confidence interval.

more pronounced when considering only the rainfall depth of a 1-h event (not shown). For LDE, the observed scaling is a sub-CC scaling or a peak-like structure (West Coast, NW Forest, and Western Cordillera). For these events, the wet time fraction is generally close to one
(90\% of wet time fractions of events are higher than 0.7 for all regions) and does not display a temperature dependence, suggesting that these scalings may not be explained by the inclusion of significant dry intervals within LDEs (at least dry spells longer than $1 \mathrm{~h}$ ). 

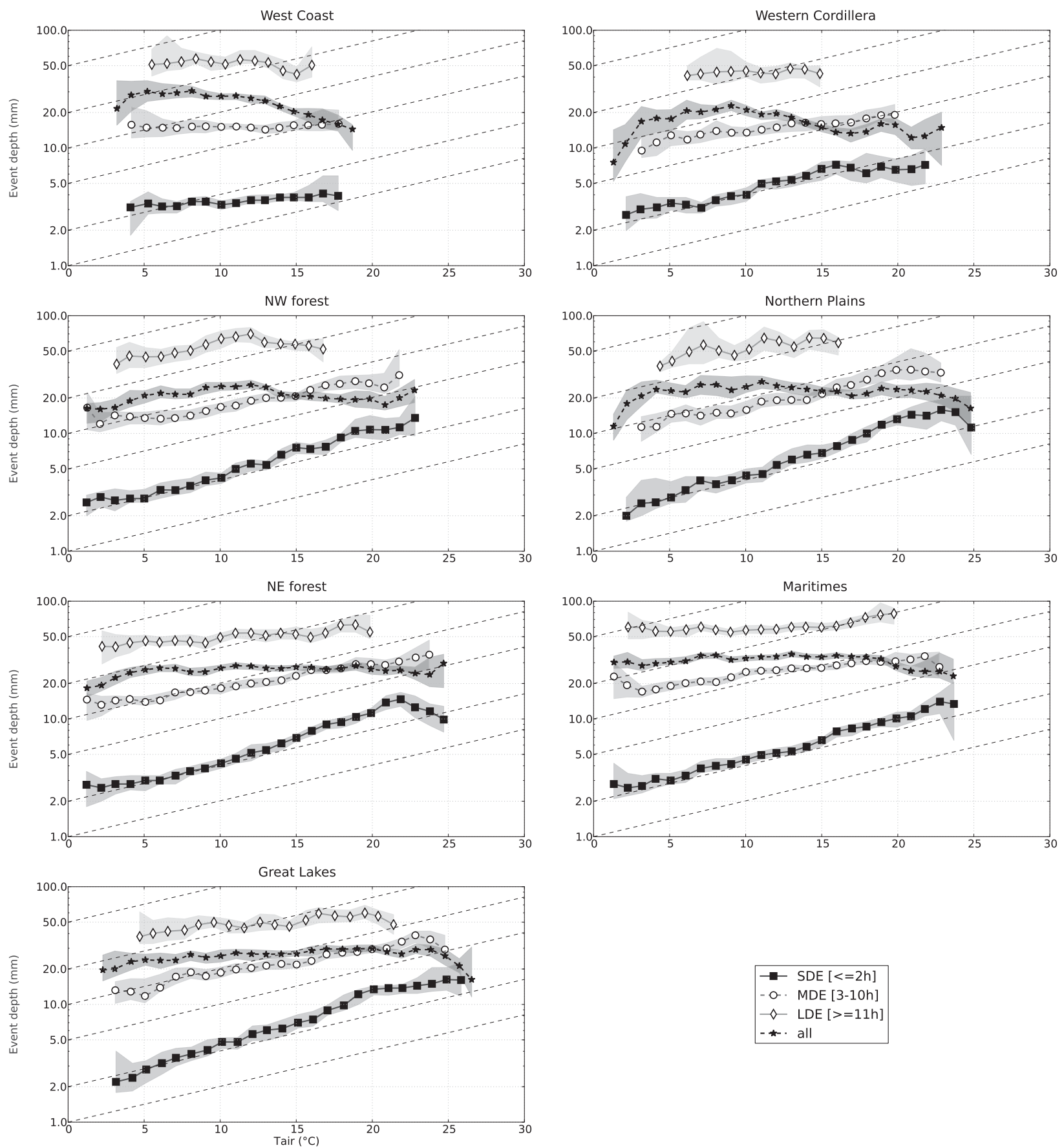

FIG. 5. Relationships between the 95th percentile of event rainfall depth and the air temperature for SDEs, MDEs, LDEs, and all events. Shaded areas represent the $95 \%$ confidence interval. Dashed lines correspond to the $7 \% \mathrm{~K}^{-1} \mathrm{CC}$ scaling. Note the logarithmic $y$ axis.

\section{Discussion and conclusions}

This study presents the different $P_{\text {extr }}-T_{a}$ relationships obtained for observed rainfall and temperature series across Canada. The factors controlling the shape of these relationships have been analyzed. Two complementary analyses were performed in order to better understand different temperature scaling patterns. The first used dewpoint temperature to evaluate the influence of relative humidity on $P_{\text {extr }}-T_{a}$ relationship. The second one focused on event rainfall characteristics in order to investigate the potential effects 
caused by a transition from a dominant synoptic regime to a more convective regime.

For all regions under study, the relationships are primarily controlled by the duration over which the rainfall intensity is computed: the longer the duration, the less pronounced was the increase of extreme rainfall intensities with temperature. This result agrees with reported results from others studies that have computed $P_{\text {extr }}{ }^{-}$ $T_{a}$ relationships for different temporal scales (e.g., Lenderink and van Meijgaard 2008; Haerter et al. 2010; Utsumi et al. 2011). Climatic regions also have a major impact on the $P_{\text {extr }}-T_{a}$ relationship. Inland regions display a very different pattern than coastal regions.

Inland regions are characterized by a super-CC temperature regime followed by level-off or peak-like structures for short durations and a sub-CC scaling for longer durations as temperature increases. The estimated relationship $P_{\text {extr }}-T_{d}$ suggested that the peak-like and level-off structures observed for the $P_{\text {extr }}-T_{a}$ relationship are due to a decrease of relative humidity as temperature rises. Other studies have already found that these kinds of $P_{\text {extr }}-T_{a}$ relationships are due to a decreasing relative humidity as air temperature rises (Hardwick Jones et al. 2010; Lenderink and van Meijgaard 2010; Lenderink et al. 2011). In these regions, super-CC and sub-CC scaling are obtained both for $P_{\text {extr }}-T_{a}$ and $P_{\text {extr }}-T_{d}$ relationships, meaning that factors other than local humidity control the relationships in these cases. One possible explanation arose from the eventbased analysis as super-CC (sub-CC) scaling is also observed for SDE (LDE) class. It suggested that these two scalings (super-CC and sub-CC) may not entirely be due to statistical effects (transition from synoptic to convective regimes for super-CC and inclusion of dry periods for sub-CC). As explained above, SDE can be associated with convective systems. In this case, two other processes can enhance the convection that are not taken into account by the increase of the atmospheric moisture-holding capacity (and thus atmospheric humidity if the relative humidity stays constant) as temperature rises. First, as shown by Renno and Ingersoll (1996), the convective available potential energy (CAPE) increases as air temperature rises. The second process is the additional latent heat released by condensation (when air humidity condenses into rainfall), which can feed back and invigorate the convection (Trenberth et al. 2003). These two processes tend to enhance convection, and thus, the low-level moisture convergence and the rainfall amount generated by the storm (Trenberth et al. 2003; Trenberth 2011) are not taken into account when considering a simple CC scaling. These theoretical considerations are supported by other studies that used cloud classification for the identification of synoptic-convective events (Berg et al. 2013; Berg and Haerter 2013). These studies have shown that the super-CC scaling is also observed for convective events in Germany. As noted earlier, the wet fraction in LDE does not vary substantially with temperature, which indicates that the observed sub-CC scaling is likely related to the dynamic processes involved in the rainfall event. In this case, the rainfall amount does not depend only on the local content of humidity in the air, but also on the moisture advected from surrounding regions. This is consistent with the fact that LDEs are associated with synoptic events (fronts, orographic).

For coastal regions, the $P_{\text {extr }}-T_{a}$ relationship displays a close-CC scaling for short durations, while a slight monotonic decrease is observed for long durations. Similar patterns were obtained for dewpoint temperature, meaning that the relative humidity remains almost constant as temperature rises, and therefore, available humidity is not a limiting factor. Event-based analysis showed that the proportion of SDE able to generate substantial amounts of rain was very small (particularly for West Coast), suggesting that the main process involved in the generation of intense rainfalls was synoptic. Thus, for long durations, the decreasing slope of scaling may be attributable to moisture advected from outside that is not taken into account by the actual record of temperature (same explanation as for inland regions for long durations). The close-CC scaling observed for short durations may be attributable to the actual content of humidity. Thus, one hypothesis is that the vertical motion of moisture is not enhanced by the air temperature as the main driver is synoptic (frontal systems). As suggested by Mishra et al. (2012), for synoptic systems the air temperature difference between the air masses may be a complementary predictor to explain high intensities for short durations.

As noted earlier, the general shape of the $P_{\text {extr }}-T_{a}$ and $P_{\text {extr }}-T_{d}$ relationships does not depend on the season. Similar results have been obtained by Maeda et al. (2012), but in Europe the reported dependence of the relationship to season is significant [as shown by Berg et al. (2009)]. This dependence can arise when the different processes that govern extreme rainfall are strongly dependent on the season. Finally, estimated $P_{\text {extr }}-T_{a}$ and $P_{\text {extr }}-T_{d}$ relationships were not sensitive to the percentile (if selected percentile was sufficiently high).

An open issue of this study concerns the impact of air temperature on the characteristics of very short-duration events (typically shorter than $1 \mathrm{~h}$ ). The hourly resolution of available series is not sufficient to accurately estimate the duration of SDEs. The consequence is that the mean and maximum intensities of these events are not accurately estimated. An adequate resolution would be 
provided by 5 -min rainfall series. However, absence of 5-min rainfall series across Canada prevents such analysis.

Ongoing works are using regional climate simulations to explore the capacity of climate model simulation to reproduce the observed $P_{\text {extr }}-T_{a}$ and $P_{\text {extr }}-T_{d}$ relationships. This point requires that the gap between observation series and model outputs be filled and the issue of the different spatial resolutions between models (spatial resolution of few tens of square kilometers) and observations (pointwise resolution) be resolved. Once this task is completed, it would be interesting to investigate the potential modification of the $P_{\text {extr }}-T_{a}$ and $P_{\text {extr }}-T_{d}$ relationships in a future climate.

Acknowledgments. This work was funded in part by the Climate Change and Adaptation Program of Natural Resources Canada and by the Consortium Ouranos on Regional Climatology and Adaptation to Climate Change. The authors also thank Catherine Savard and Julie Drapeau of the Ministère du Développement Durable, de l'Environnement et des Parcs (MDDEP) of the Québec government and Mr. Philipp Jarrett from Environment Canada, who provided the observed series. The authors also thank three referees for their constructive comments.

\section{REFERENCES}

Alexander, L. V., and Coauthors, 2006: Global observed changes in daily climate extremes of temperature and precipitation. J. Geophys. Res., 111, D05109, doi:10.1029/2005JD006290.

Allan, R. P., and B. J. Soden, 2008: Atmospheric warming and the amplification of precipitation extremes. Science, 321, 14811484, doi:10.1126/science.1160787.

Allen, M. R., and W. J. Ingram, 2002: Constraints on future changes in climate and the hydrologic cycle. Nature, 419, 224-232, doi:10.1038/nature01092.

Berg, P., and J. O. Haerter, 2013: Unexpected increase in precipitation intensity with temperature-A result of mixing of precipitation types? Atmos. Res., 119, 56-61, doi:10.1016/ j.atmosres.2011.05.012.

, — , P. Thejll, C. Piani, S. Hagemann, and J. H. Christensen, 2009: Seasonal characteristics of the relationship between daily precipitation intensity and surface temperature. J. Geophys. Res., 114, D18102, doi:10.1029/2009JD012008.

_ C. Moseley, and J. O. Haerter, 2013: Strong increase in convective precipitation in response to higher temperatures. Nat. Geosci., 6, 181-185, doi:10.1038/ngeo1731.

Canadian Standards Association, 2012: Development, interpretation, and use of rainfall intensity-duration-frequency (IDF) information: Guideline for Canadian water resources practitioners. Tech. Rep., 190 pp.

Dunkerley, D., 2008: Identifying individual rain events from pluviograph records: A review with analysis of data from an Australian dryland site. Hydrol. Processes, 22, 5024-5036, doi:10.1002/hyp.7122.

Easterling, D. R., J. L. Evans, P. Ya. Groisman, T. R. Karl, K. E. Kunkel, and P. Ambenje, 2000: Observed variability and trends in extreme climate events: A brief review. Bull. Amer. Meteor. Soc., 81, 417-426, doi:10.1175/1520-0477(2000)081<0417: OVATIE $>2.3 . \mathrm{CO} ; 2$.

Efron, B., 1979: Bootstrap methods: Another look at the jackknife. Ann. Stat., 7, doi:10.1214/aos/1176344552.

_ Chapman \& Hall, 436 pp.

Haerter, J. O., and P. Berg, 2009: Unexpected rise in extreme precipitation caused by a shift in rain type? Nat. Geosci., 2, 372-373, doi:10.1038/ngeo523.

,-- , and S. Hagemann, 2010: Heavy rain intensity distributions on varying time scales and at different temperatures. J. Geophys. Res., 115, D17102, doi:10.1029/2009JD013384.

Hand, W. H., N. I. Fox, and C. G. Collier, 2004: A study of twentieth-century extreme rainfall events in the United Kingdom with implications for forecasting. Meteor. Appl., 11, 15-31, doi:10.1017/S1350482703001117.

Hardwick Jones, R., S. Westra, and A. Sharma, 2010: Observed relationships between extreme sub-daily precipitation, surface temperature, and relative humidity. Geophys. Res. Lett., 37, L22805, doi:10.1029/2010GL045081.

Huntington, T., 2006: Evidence for intensification of the global water cycle: Review and synthesis. J. Hydrol., 319, 83-95, doi:10.1016/j.jhydrol.2005.07.003.

Kharin, V. V., F. W. Zwiers, X. Zhang, and G. C. Hegerl, 2007: Changes in temperature and precipitation extremes in the IPCC ensemble of global coupled model simulations. J. Climate, 20, 1419-1444, doi:10.1175/JCLI4066.1.

,,--- , and M. Wehner, 2013: Changes in temperature and precipitation extremes in the CMIP5 ensemble. Climatic Change, 119, 345-357, doi:10.1007/s10584-013-0705-8.

Lenderink, G., and E. van Meijgaard, 2008: Increase in hourly precipitation extremes beyond expectations from temperature changes. Nat. Geosci., 1, 511-514, doi:10.1038/ngeo262.

- , and - , 2009: Unexpected rise in extreme precipitation caused by a shift in rain type? Nat. Geosci., 2, 373-373, doi:10.1038/ngeo524.

—_, and —_, 2010: Linking increases in hourly precipitation extremes to atmospheric temperature and moisture changes. Environ. Res. Lett., 5, 025208, doi:10.1088/1748-9326/ 5/2/025208.

—_, H. Y. Mok, T. C. Lee, and G. J. van Oldenborgh, 2011: Scaling and trends of hourly precipitation extremes in two different climate zones-Hong Kong and the Netherlands. Hydrol. Earth Syst. Sci., 15, 3033-3041, doi:10.5194/ hess-15-3033-2011.

Maeda, E., N. Utsumi, and T. Oki, 2012: Decreasing precipitation extremes at higher temperatures in tropical regions. Nat. Hazards, 64, 935-941, doi:10.1007/s11069-012-0222-5.

Mailhot, A., I. Beauregard, G. Talbot, D. Caya, and S. Biner, 2012: Future changes in intense precipitation over Canada assessed from multi-model NARCCAP ensemble simulations. Int. J. Climatol., 32, 1151-1163, doi:10.1002/joc.2343.

Metcalfe, J. R., B. Routledge, and K. Devine, 1997: Rainfall measurement in Canada: Changing observational methods and archive adjustment procedures. J. Climate, 10, 92-101, doi:10.1175/1520-0442(1997)010<0092:RMICCO >2.0.CO;2.

Min, S., X. Zhang, F. Zwiers, and G. Hegerl, 2011: Human contribution to more-intense precipitation extremes. Nature, 470, 378-381, doi:10.1038/nature09763.

Mishra, V., J. M. Wallace, and D. P. Lettenmaier, 2012: Relationship between hourly extreme precipitation and local air temperature in the United States: Extreme precipitation and 
temperature. Geophys. Res. Lett., 39, L16403, doi:10.1029/ 2012GL052790.

O'Gorman, P. A., and T. Schneider, 2009: The physical basis for increases in precipitation extremes in simulations of 21st-century climate change. Proc. Natl. Acad. Sci. USA, 106, 14773-14 777, doi:10.1073/pnas.0907610106.

Pall, P., M. R. Allen, and D. A. Stone, 2007: Testing the ClausiusClapeyron constraint on changes in extreme precipitation under $\mathrm{CO}_{2}$ warming. Climate Dyn., 28, 351-363, doi:10.1007/ s00382-006-0180-2.

Plummer, D. A., and Coauthors, 2006: Climate and climate change over North America as simulated by the Canadian RCM. J. Climate, 19, 3112-3132, doi:10.1175/JCLI3769.1.

Renno, N. O., and A. P. Ingersoll, 1996: Natural convection as a heat engine: A theory for CAPE. J. Atmos. Sci., 53, 572-585, doi:10.1175/1520-0469(1996)053<0572:NCAAHE >2.0.CO;2.

Schneider, T., P. A. O'Gorman, and X. J. Levine, 2010: Water vapor and the dynamics of climate changes. Rev. Geophys., 48, RG3001, doi:10.1029/2009RG000302.
Shaw, S. B., A. A. Royem, and S. J. Riha, 2011: The relationship between extreme hourly precipitation and surface temperature in different hydroclimatic regions of the United States. J. Hydrometeor., 12, 319-325, doi:10.1175/2011JHM1364.1.

Sun, Y., S. Solomon, A. Dai, and R. Portmann, 2007: How often will it rain? J. Climate, 20, 4801-4818, doi:10.1175/ JCLI4263.1.

Trenberth, K., 2011: Changes in precipitation with climate change. Climate Res., 47, 123-138, doi:10.3354/cr00953.

—, A. Dai, R. Rasmussen, and D. Parsons, 2003: The changing character of precipitation. Bull. Amer. Meteor. Soc., 84, 12051217, doi:10.1175/BAMS-84-9-1205.

Utsumi, N., S. Seto, S. Kanae, E. E. Maeda, and T. Oki, 2011: Does higher surface temperature intensify extreme precipitation? Geophys. Res. Lett., 38, L16708, doi:10.1029/ 2011 GL048426.

Wehrens, R., H. Putter, and L. M. Buydens, 2000: The bootstrap: A tutorial. Chemom. Intell. Lab. Syst., 54, 35-52, doi:10.1016/ S0169-7439(00)00102-7. 